Running heads: YOUNG PEOPLE'S INTENTIONS TO DONATE MONEY

\title{
KNOWLES ET AL.
}

Predictors of Young People's Charitable Intentions to Donate Money:

An Extended Theory of Planned Behavior Perspective

SIMON R. KNOWLES

Swinburne University of Technology

Melbourne, Australia

\author{
MELISSA K. HYdE ${ }^{1}$ AND KATHERINE M. WhITE \\ School of Psychology and Counselling \\ Queensland University of Technology \\ Queensland, Australia
}

\begin{abstract}
An extended theory of planned behavior (TPB) was used to predict young people's intentions to donate money to charities in the future. Students $(N=210 ; 18-24$ years) completed a questionnaire assessing their attitude, subjective norm, perceived behavioral control (PBC), moral obligation, past behavior, and intentions toward donating money. Regression analyses revealed that the extended TPB explained $61 \%$ of the variance in intentions to donate money. Attitude, PBC, moral norm, and past behavior predicted intentions, representing future targets for charitable-giving interventions.
\end{abstract}

Nonprofit charitable organizations play a crucial role in providing much-needed services and support to individuals in need in society, both at the local and the international level (Cheung \& Chan, 2000). The provision of services and support, however, is dependent on public generosity to perform two key behaviors characteristic of charitable giving: donation of money and donation of time (Lee \& Chang, 2007).

\footnotetext{
${ }^{1}$ Correspondence concerning this article should be addressed to Melissa Hyde, School of Psychology and Counselling, Queensland University of Technology, Victoria Park Road, Kelvin Grove, Queensland, Australia 4059. E-mail: mk.hyde@qut.edu.au
} 
While the giving of money and time in Australia has increased over the past decade (Lyons, McGregorLowndes, \& O’Donoghue, 2006), Australians still donate less money and time than do people living in other developed countries (Industry Commission, 1995; Volunteering Australia, 2002). In a recent international comparison of national giving levels as a percentage of gross domestic product (GDP), for example, Australia ranked fourth $(0.69 \%)$, below the United States (1.67\%), United Kingdom (0.73\%), and Canada (0.72\%; Charities Aid Foundation, 2005). In 2006, of the Australians surveyed, 77\% had donated money in the past year to a charitable organization, with the highest percentage of donors in the 45- to 54-year age bracket (82.6\%), while the lowest percentage was in the 18- to 24-year age bracket (61.7\%; Australian Bureau of Statistics [ABS], 2007). In view of the potential for increased giving in Australia — especially among 18- to 24-year-olds_and the continued reliance of nonprofit charitable organizations on individual generosity in all developed countries, it is important to understand the factors and circumstances that encourage charitable giving.

While there has been much research undertaken on charitable giving, several criticisms have been raised about this research. First, much of the research on the factors influencing charitable giving have focused on demographic characteristics (e.g., Bryant, Jeon-Slaughter, Kang, \& Tax, 2003; Cheung \& Chan, 2000; Konkoly \& Perloff, 1990; Lee \& Chang, 2007), which, while important, do not provide an explanation for why people choose to engage in charitable giving and do not provide targets for strategies to encourage charitable giving (Lee, Piliavin, \& Call, 1999; Smith \& McSweeney, 2007). Furthermore, these constructs would be expected to have a more distal influence on behavior, informing the personal beliefs and motivations of the individual engaging in charitable giving (Lee et al., 1999; Penner, 2004).

Second, as a result of focusing on demographic characteristics, much of the research does not employ a well validated theoretical framework that can account for the range of personal (e.g., attitudes, self-efficacy) and social (e.g., normative approval) factors impacting on the decision to engage in charitable giving (Greenslade \& White, 2005; Smith \& McSweeney; Warburton \& Terry, 2000). Third, there has been a disproportionate focus on volunteering research, with few studies providing an examination of the predictors of the donation of money to charitable or relief organizations (Cheung \& Chan, 2000; Lyons et al., 2006; Steinberg \& Rooney, 2005).

Understanding the donation of money is particularly important to inform strategies or campaigns designed to increase charitable giving, as donating money is the form of assistance most likely to be provided in both noncrisis and crisis situations (Piferi, Jobe, \& Jones, 2006; St. John \& Fuchs, 2002). It is a behavior that most people can 
perform if they have the necessary resources since it involves little risk and requires only a small amount of effort (Avdeyeva, Burgetova, \& Welch, 2006). In light of these criticisms, we aim to contribute to the charitable giving research by using an extended version of a well validated theoretical framework - the theory of planned behavior (Ajzen, 1991) — to understand the psychosocial determinants of young people's decisions to donate money. The Extended Theory of Planned Behavior Model

The theory of planned behavior (TPB; Ajzen, 1991) maintains that intentions (i.e., readiness to act) are the most proximal determinant of behavior. Intentions, in turn, are influenced by attitude (positive or negative evaluations of performing a behavior), subjective norm (perceived social pressure and expectations to perform or not perform a behavior), and perceived behavioral control (PBC; perceived ease or difficulty of performing a behavior, also thought to be a direct predictor of behavior; Ajzen, 1991). Support for the TPB model has been demonstrated in a number of meta-analyses, including Armitage and Conner's (2001a) study, which found that the TPB accounted for an average of $39 \%$ of the variance in intentions and $27 \%$ of the variance in behavior.

To date, a small number of studies have applied the TPB in the charitable giving context (e.g., Greenslade \& White, 2005; Harrison, 1995; Okun \& Sloane, 2002; Warburton \& Terry, 2000), with only one study using the TPB to examine the donation of money (Smith \& McSweeney, 2007). Taken together, these charitable giving studies support the use of the TPB as a framework in this context, as attitude, subjective norm, and PBC all emerge as significant predictors of intentions; and intention (but not PBC) emerges as a significant predictor of behavior.

For the donation of money specifically, Smith and McSweeney (2007) used hierarchical regression analysis to assess the predictors of intentions to donate and actual money donation. The results of their study, using an extended TPB model, revealed that the TPB components of attitude, subjective norm, and PBC significantly predicted intentions to donate money, and intentions significantly predicted money donation. In another study using the theory of reasoned action (the predecessor of the TPB; Fishbein \& Ajzen, 1975) to predict intentions to donate money, attitude and subjective norm also emerged as significant predictors, providing further support for the constructs in the TPB model in understanding the decision to donate money (Konkoly \& Perloff, 1990).

Several studies have also employed revisions of the TPB model to incorporate additional influences relevant to the behavior under study (for a review, see Conner \& Armitage, 1998). An extended TPB model incorporating the influence of perceived moral obligation, for instance, has been successfully applied to the prediction of altruistic or charitable behaviors, such as volunteering time (Warburton \& Terry, 2000), blood donation (Armitage \& Conner, 
2001b), and organ donation (Hyde \& White, 2009). Moral obligation, referred to as moral norm or personal norm, is conceptually distinct from subjective norm and reflects feelings of personal responsibility or duty to perform a given behavior (Manstead, 2000).

In acknowledgement of the relevance of moral norm to the charitable giving context (Cheung \& Chan, 2000; Oosterhof, Heuvelman, \& Peters, 2009; Radley \& Kennedy, 1995), Smith and McSweeney (2007) adopted an extended TPB model incorporating moral norm to predict intentions to donate money in a sample of 227 general community members aged 17 to 82 years. After controlling for the effects of demographic characteristics, standard TPB variables, and past behavior, moral norm emerged as a significant predictor of people's intentions to donate money. Given the potential importance of perceived moral obligation in understanding decisions to donate money, we incorporated this construct in an extended TPB model.

The Present Study

The present study represents an attempt to replicate and build on previous research using an extended TPB model (incorporating attitude, subjective norm, PBC, moral norm, and past behavior) to understand the determinants of people's decisions to donate money to charitable organizations. Given that young adults in the 18- to 24-year age range currently represent the lowest percentage of Australian donors (ABS, 2007), we focused specifically on the decision making of young people about donating money. A focus on younger individuals differs from Smith and McSweeney's (2007) study, which included participants from the general community with a mean age of 44.2 years (approximating the age range most likely to donate, according to ABS statistics; ABS, 2007).

The focus on young people in the current study is also particularly important to encourage lifelong charitable giving practices as a result of the association established in previous research suggesting that charitable giving experiences in youth translate into increased charitable giving in adulthood (e.g., Hart, Donnelly, Youniss, \& Atkins, 2002; Metz, McLellan, \& Youniss, 2003). On the basis of previous TPB and charitable giving research, we expect that young people will have stronger intentions to donate money if they have a positive attitude toward donating money, perceive social pressure to donate, perceive that they have control over donating, feel a moral obligation to donate money, and have donated money on a more frequent basis in the past.

Method

\section{Participants and Procedure}


Prior to conducting the study, we obtained ethical approval from the University Human Research Ethics Committee. Participants ( $N=210,40$ males, 170 females) were university students, ranging in age from 18 to 24 years ( $M=19.1$ years, $S D=1.5 ; 86.3 \%$ Caucasian $)$, who were recruited from a metropolitan university in Victoria, Australia (Table 1). Students volunteered to complete a questionnaire assessing the standard TPB measures (attitude, subjective norm, PBC, intentions), past behavior, and moral norm (broadly based on Armitage \& Conner, 2001b) toward donating money to a charity or individuals in need in the future (donating money). Table 2 presents the number of times students self-reported donating to a charity in the past year and the average amount donated (AUD\$). Tables 3 and 4 present the commonly reported reasons for choosing to donate and not donate, respectively.

-INSERT TABLE 1 ABOUT HERE ${ }^{\mathrm{A}}$ -

-INSERT TABLE 2 ABOUT HERE ${ }^{\mathrm{B}}$ -

-INSERT TABLE 3 ABOUT HERE ${ }^{\mathrm{C}}$ -

-INSERT TABLE 4 ABOUT HERE ${ }^{\text {D }}$

\section{Measures}

All of the items were rated on 7-point Likert-type response scales ranging from 0 to 6, unless specified otherwise. Responses were coded so that higher values reflect higher levels of the variable. Items were based broadly on Armitage and Conner (2001b).

Intention. There were seven items that assessed the strength of intention to donate money in the future. A sample item is "I intend to donate money to charities in the future," which was rated on a 7-point scale ranging from 0 (definitely do not) to 6 (definitely do). The items were averaged to create a reliable intention scale $(\alpha=.96)$.

Attitude. We used six, 7-point semantic-differential format items as a measure of attitude toward donating money. Sample items are "My donating money to charities in the future is ..." bad-good, and useless-useful. The six items were averaged to form a reliable attitude scale $(\alpha=.93)$. 
Subjective norm. There were three items that comprised the measure of subjective norm. A sample item is "People who are important to me want me to donate money to charities," which was rated on a 7-point scale ranging from 0 (unlikely) to 6 (likely). The items were averaged to create a reliable subjective norm scale $(\alpha=.78)$.

Perceived behavioral control (PBC). We used six items to measure the construct of PBC. Sample items are "I believe I have the ability to donate money to charities in the future," which was rated from 0 (definitely do not) to 6 (definitely do); and "Whether or not I donate money to charities in the future is entirely up to me," which was rated 0 (strongly disagree) to 6 (strongly agree). Items were averaged to form a reliable measure of PBC $(\alpha=.87)$.

Moral norm. Moral norm was measured using three items. A sample item is "It would go against my principles if I did not donate money to charities in the future," which was rated on a 7-point scale ranging from 0 (strongly disagree) to 6 (strongly agree). Items were averaged to serve as a measure of moral norm $(\alpha=.88)$.

Past behavior. We measured past behavior with a single item using a 5-point scale. The item is "Have you donated money to charity in the past year?" which was rated from 1 (no) to 3 to 5 (> 11 times a year).

\section{Results}

\section{Descriptive Analyses}

The number of times young people had donated money in the past year and the average amount donated are presented in Table 2. The majority of young people had donated 1 to 2 times $(n=74 ; 35.3 \%)$ or 3 to 5 times $(n=66$; $31.4 \%)$ in the past year. Those who donated had contributed up to AUD\$60 $(n=149 ; 72.0 \%)$ during the past year. Those participants who had donated money to one or more charities in the past year were asked to report why they had chosen to donate (Table 3). Those who donated infrequently or not at all were asked to indicate the reasons why they had chosen not to donate money to charitable organizations (Table 4). As shown in Table 3, the three most common reasons for donating were because the charity had personal significance for the donor (e.g., donating to the Anti-Cancer Council because a family member has cancer), respondents' trust and belief in the values and views of the charity (e.g., knowing the money will be put to good use, the charity's goals are admirable), and the charity benefiting a specific population (e.g., children). The most commonly cited reason for declining to donate was financial difficulty (i.e., having no money to spare, not being able to afford to donate; Table 4).

Descriptive statistics including item means, standard deviations, and bivariate correlations between the standard TPB variables (i.e., attitude, subjective norm, PBC), moral norm, past behavior, and intention are presented in Table 5. Inspection of the correlation matrix reveals the TPB predictors, moral norm, and past behavior as 
significantly and moderately correlated with intention. Attitude and PBC emerged as the strongest correlates of intention to donate money.

\section{-INSERT TABLE 5 ABOUT HERE ${ }^{\mathrm{E}}$ -}

To test the specified relationships in the extended TPB model, a hierarchical regression analysis was conducted, predicting intention to donate money to charities in the future. The measures of attitude, subjective norm, and PBC were entered in the first step of the regression equation, moral norm was entered in the second step after controlling for the TPB variables, and past behavior was included in the third step.

As shown in Table 6, the linear combination of attitude and PBC accounted for 52\% (51.0\% adjusted) of the variance in intention to donate money to charities in the future, $F(3,204)=72.82, p<.001$. The addition of moral norm to the model accounted for an increase of $5 \%$ of the variance in intention to donate, $F(4,203)=67.54, p<$ .001 . Including past behavior in Step 3 explained a further $3 \%$ of the variance, $F(5,202)=61.76, p<.001$. Once all of the variables were entered into the equation, the measures of attitude, PBC, moral norm, and past behavior (but not subjective norm) emerged as significant predictors, accounting for a total of $61 \%(59.5 \%$ adjusted) of the variance in young people's intentions to donate money to charities in the future.

\section{-INSERT TABLE 6 ABOUT HERE ${ }^{\mathrm{F}}-$}

\section{Discussion}

In conducting this study, we aimed to address previous criticisms of the charitable giving literature by using a revised version of a well validated theoretical framework, the TPB, to examine the decision to donate money to charitable organizations. By using this approach, we add to the TPB literature also, given that only one study (Smith \& McSweeney, 2007) has previously used an extended version of the model to understand people's decisions to donate money to charity. We focused on young people's decisions to donate money only, given the disproportionate emphasis of charitable giving research on volunteering, the fact that donating money is the form of assistance most commonly provided by individuals to charities, and the potential for increased giving in the Australian population, especially among young people for whom lifelong habits of charitable giving can be encouraged. Specifically, we 
examined the contribution of attitude, subjective norm, PBC, moral norm, and past behavior to the prediction of young people's intentions to donate money to charitable organizations.

The extended TPB was able to explain $61 \%$ of the variance in young people's intentions to donate money. Attitude, PBC, moral norm, and past behavior emerged as significant predictors of intentions to donate money. In contrast to previous research (e.g., Konkoly \& Perloff, 1990; Smith \& McSweeney, 2007), subjective norm did not emerge as a predictor of young people's intentions to donate money. Together, the results of the study provide some support for the hypothesized relationships between the extended TPB predictors and intentions to donate money. Young people who held more favorable attitudes toward donating money, perceived that they had control over donating, perceived a moral obligation to donate money, and had donated money more frequently in the past possessed stronger intentions to donate money in the future.

The findings comprise potential areas for future intervention to encourage young people to donate money in the future. First, the results of the current study suggest that increasing positive attitudes toward charitable giving may encourage donation. To increase (or maintain) positive attitudes toward charitable giving, it may be useful for campaigns to remind the community of how their contributions have translated (or will translate in the future) into tangible benefits for the recipients of aid at local, national, and international levels. This approach may also have the added benefit of increasing trust in the practices of the charitable organization: a reason that is commonly cited as a factor in the decision to engage in charitable giving in the wider literature (Australian Council of Social Services, 2005).

Second, the contribution of PBC to the prediction of intentions to donate money suggests that young people's perceptions of their capacity to be able to donate money affects their intentions (also see Smith \& McSweeney, 2007). Unsurprisingly, based on the reasons for non-donation, the perception of low efficacy or control for donating money appears to be primarily a result of individual's realization that — especially as university students - they lack the necessary financial resources to donate when they wish to make a contribution. Given that donating money is considered to be a behavior that is low in risk and effort (i.e., a behavior that is easy to perform; Avdeyeva et al., 2006), young people with low efficacy could be encouraged to consider "giving while they can," when finances are available. It may also be worth emphasizing, particularly for those who donate infrequently or not at all, that "a little goes a long way." Young people should be reassured that even very small contributions are appreciated and needed. 
The final key finding in the current study is highlighted by the emergence of a perception of moral responsibility or obligation (moral norm) to donate as influencing intentions to donate money in the future. The importance of moral norm as a predictor of intentions concurs with both TPB-based (e.g., Smith \& McSweeney, 2007; Warburton \& Terry, 2000) and more general charitable giving research (Cheung \& Chan, 2000; Oosterhof et al., 2009; Radley \& Kennedy, 1995). Young people could be encouraged to foster a sense of personal responsibility by portraying the donation of money to a charitable organization as the right or morally correct thing to do.

Given that young people most commonly reported in the current study that they donated to charities that have personal significance for them, it may be useful to emphasize the personal connection between the potential donors and recipients as a way of promoting a sense of moral obligation to donate. For instance, an Australian study examining charitable giving in the context of the Ash Wednesday bushfires found that the strongest predictor of the amount of money donated was a perceived personal obligation to assist the victims of the bushfires (Amato, Ho, \& Patridge, 1984). Alternatively, to increase a sense of moral obligation to donate, young people could be asked to consider if they know anyone who has benefited, or if they themselves may benefit in the future, from the services the charity provides before they make a decision about giving money to charity.

Although the current study has several strengths — such as the use of an established theoretical frameworkthe findings should be interpreted in light of the study's limitations, including the higher proportion of female and Caucasian participants, the focus on university students who may not be representative of the general population of young people, and the reliance on a self-report questionnaire. Future studies should recruit a more representative sample of young people, including young working professionals, as well as a higher proportion of male and nonCaucasian participants. Future research may also benefit from an in-depth qualitative analysis of the motivations of this population underlying their decisions to donate money to charity.

The major limitation of the present study is the absence of a prospective measure of actual donation behavior. Although not a measure of behavior, intentions are the most consistent predictor of charitable giving behavior (e.g., Greenslade \& White, 2005; Smith \& McSweeney, 2007; Warbuton \& Terry, 2000) and can act as a suitable proxy measure for behavior when actual behavior is not measured (Chacón, Vecina, \& Davila, 2007; Schlumpf et al., 2008). Future studies should test the full TPB model, including intentions and behavior and incorporating the additional construct of moral norm, to understand further young people's decisions about donating money to charity. 
Overall, in addition to providing some support for the utility of an extended TPB framework in the charitable giving context, the results of the current study suggest three key variables that may be targeted in future charitable campaign efforts: attitude, perceived behavioral control, and moral norm. Given the continued reliance of charitable organizations on public generosity to donate money, and the fact that there is a potential for increased charitable contributions among young people, it is important to further our understanding of the psychosocial factors that influence young people's charitable giving in response to local, national, and international appeals for aid.

References

Ajzen, I. (1991). Theory of planned behavior. Organizational Behavior and Human Decision Processes, 50, 179211.

Amato, P. R., Ho, R., \& Partridge, S. (1984). Responsibility attribution and helping behaviour in the Ash Wednesday bushfires. Australian Journal of Psychology, 36, 191-203.

Armitage, C. J., \& Conner, M. (2001a). Efficacy of the theory of planned behaviour: A meta-analytic review. British Journal of Social Psychology, 40, 471-489.

Armitage, C. J., \& Conner, M. (2001b). Social cognitive determinants of blood donation. Journal of Applied Social Psychology, 31, 1431-1457.

Australian Bureau of Statistics (ABS). (2007). 4441.0: Voluntary Work Australia, 2006. Retrieved July 10, 2008 from http://www.abs.gov.au/AUSSTATS/subscriber.nsf/log?openagent\&44410_2006.pdf\&4441.0\&Publication\& C52862862C082577CA25731000198615\&0\&2006\&09.07.2007\&Latest

Australian Council of Social Services (ACOSS). (2005). Giving Australia: Research on philanthropy in Australia. Canberra, Australia: Department of Family Services. Retrieved March 29, 2008 from http://www.partnerships.gov.au/philanthropy/philanthropy research.shtml\#FinalReports

Avdeyeva, T. V., Burgetova, K., Welch, I. D. (2006). To help or not to help? Factors that determined helping responses to Katrina victims. Analysis of Social Issues and Public Policy, 6, 159-173.

Bryant, W. K., Jeon-Slaughter, H., Kang, H., \& Tax, A. (2003). Participation in philanthropic activities: Donating money and time. Journal of Consumer Policy, 26, 43-73.

Chacón, F., Vecina, M. L., \& Dávila, M. C. (2007). The three-stage model of volunteers’ duration of service. Social Behavior and Personality, 35, 627-642. 
Charities Aid Foundation. (2005). International comparisons of charitable giving November 2006: CAF briefing paper. Retrieved July 10, 2008 from http://www.cafonline.org/pdf/International\%20\%20Giving\%20highlights.pdf

Cheung, C. K., \& Chan, C. M. (2000). Social-cognitive factors of donating money to charity, with special attention to an international relief organization. Evaluation and Program Planning, 23, 241-253.

Conner, M., \& Armitage, C. J. (1998). Extending the theory of planned behavior: A review and avenues for further research. Journal of Applied Social Psychology, 28, 1429-1464.

Fishbein, M., \& Ajzen, I. (1975). Belief, attitude, intention, and behavior: An introduction to theory and research. Reading, MA: Addison-Wesley.

Greenslade, J. H., \& White, K. M. (2005). The prediction of above-average participation in volunteerism: A test of the theory of planned behavior and the Volunteers Functions Inventory in older Australian adults. Journal of Social Psychology, 145, 155-172.

Harrison, D. A. (1995). Volunteer motivation and attendance decisions: Competitive theory testing in multiple samples from a homeless shelter. Journal of Applied Psychology, 80, 371-385.

Hart, D., Donnelly, T. M., Youniss, J., \& Atkins, R. (2007). High school community service as a predictor of adult voting and volunteering. American Educational Research Journal, 44, 197-219.

Hyde, M. K., \& White, K. M. (2009). To be a donor or not to be? Applying an extended theory of planned behavior to predict posthumous organ donation intentions. Journal of Applied Social Psychology, 39, 880-900.

Industry Commission. (1995). Charitable organisations in Australia (Report No. 45). Retrieved July 11, 2008 from http://www.pc.gov.au/_data/assets/pdf_file/0007/6991/45charit.pdf

Konkoly, T. H., \& Perloff, R. M. (1990). Applying the theory of reasoned action to charitable intent. Psychological Reports, 67, 91-94.

Lee, L., Piliavin, J. A., \& Call, V. R. A. (1999). Giving time, money, and blood: Similarities and differences. Social Psychology Quarterly, 62, 276-290.

Lee, Y., \& Chang, C. (2007). Who gives what to charity? Characteristics affecting donation behavior. Social Behavior and Personality, 35, 1173-1180.

Lyons, M., McGregor-Lowndes, M., \& O’Donoghue, P. (2006). Researching giving and volunteering in Australia. Australian Journal of Social Issues, 41, 385-397. 
Manstead, A. S. R. (2000). The role of moral norm in the attitude-behavior relation. In D. J. Terry \& M. A. Hogg (Eds.), Attitudes, behavior, and social context (pp. 11-30). Mahwah, NJ: Lawrence Erlbaum.

Metz, E., McLellan, J., \& Youniss, J. (2003). Types of voluntary service and adolescents' civic development. Journal of Adolescent Research, 18, 188-203.

Okun, M. A., \& Sloane, E. S. (2002). Application of planned behavior theory to predicting volunteer enrollment by college students in a campus-based program. Social Behavior and Personality, 30, 243-250.

Oosterhof, L., Heuvelman, A., \& Peters, O. (2009). Donation to disaster relief campaigns: Underlying social cognitive factors exposed. Evaluation and Program Planning, 32, 148-157.

Penner, L. A. (2004). Volunteerism and social problems: Making things better or worse? Journal of Social Issues, $60,645-666$

Piferi, R. L., Jobe, R. L., \& Jones, W. H. (2006). Giving to others during national tragedy: The effects of altruistic and egoistic motivations on long-term giving. Journal of Social and Personal Relationships, 23, 171-184.

Radley, A., \& Kennedy, M. (1995). Charitable giving by individuals: A study of attitudes and practice. Human Relations, 48, 685-709.

Schlumpf, K. S., Glynn, S. A., Schreiber, G. B., Wright, D. J., Steele., W. R., Tu, Y., et al. (2008). Factors influencing donor return. Transfusion, 48, 264-272.

Smith, J. R., \& McSweeney, A. (2007). Charitable giving: The effectiveness of a revised theory of planned behaviour model in predicting donating intentions and behaviour. Journal of Community and Applied Social Psychology, 17, 363-386.

St. John, C., \& Fuchs, J. (2002). The heartland responds to terror: Volunteering after the bombing of the Murrah Federal Building. Social Science Quarterly, 83, 397-415.

Steinberg, K. S., \& Rooney, P. M. (2005). America gives: A survey on Americans' generosity after September 11. Nonprofit and Voluntary Sector Quarterly, 34, 110-135.

Volunteering Australia. (2002). Information sheet: Volunteering in Australia. Facts and figures. Retrieved July 10, 2008 from http://www.volunteernetwork.org.au/webresources/Volunteering\%20in\%20Australia\%20\%20Facts $\% 20$ and $\% 20$ Figures.pdf

Warburton, J., \& Terry, D. J. (2000). Volunteer decision making by older people: A test of a revised theory of planned behavior. Basic and Applied Social Psychology, 22, 245-257. 
Table 1

Demographic Profile of Respondents

\begin{tabular}{|c|c|c|c|c|}
\hline & $M$ & $S D$ & $n$ & $\%$ \\
\hline Age & 19.1 & 1.5 & & \\
\hline \multicolumn{5}{|l|}{ Gender } \\
\hline Male & & & 40 & 19.1 \\
\hline Female & & & 170 & 80.9 \\
\hline \multicolumn{5}{|l|}{ Ethnicity } \\
\hline Caucasian & & & 177 & 86.4 \\
\hline Non-Caucasian & & & 28 & 13.6 \\
\hline \multicolumn{5}{|l|}{ Work status } \\
\hline Full-time & & & 4 & 1.9 \\
\hline Part-time & & & 102 & 48.8 \\
\hline Casual & & & 63 & 30.2 \\
\hline Unemployed & & & 40 & 19.1 \\
\hline \multicolumn{5}{|l|}{ Annual income } \\
\hline$<\$ 10,000$ & & & 155 & 76.4 \\
\hline$\$ 10,001-\$ 20,000$ & & & 40 & 19.7 \\
\hline$\$ 20,001-\$ 30,000$ & & & 5 & 2.5 \\
\hline$\$ 30,001-\$ 40,000$ & & & 3 & 1.4 \\
\hline \multicolumn{5}{|l|}{ Student status } \\
\hline Full-time & & & 194 & 92.8 \\
\hline Part-time & & & 15 & 7.2 \\
\hline
\end{tabular}

Note. $N=210$. 
Table 2

Number of Times Donated in the Past Year and Average Amount Donated

\begin{tabular}{|c|c|c|}
\hline & $n$ & $\%$ \\
\hline \multicolumn{3}{|c|}{ Number of times donated } \\
\hline None & 29 & 13.8 \\
\hline $1-2$ times & 74 & 35.3 \\
\hline $3-5$ times & 66 & 31.4 \\
\hline 6-10 times & 21 & 10.0 \\
\hline$\geq 11$ times & 20 & 9.5 \\
\hline \multicolumn{3}{|c|}{ Average amount donated (in AUD\$) } \\
\hline None & 25 & 12.1 \\
\hline$\leq \$ 10.00$ & 54 & 26.1 \\
\hline$\$ 10.01-\$ 20.00$ & 57 & 27.5 \\
\hline$\$ 20.01-\$ 40.00$ & 24 & 11.6 \\
\hline$\$ 40.01-\$ 60.00$ & 14 & 6.8 \\
\hline$\$ 60.01-\$ 80.00$ & 8 & 3.9 \\
\hline$\$ 80.01-\$ 100.00$ & 8 & 3.9 \\
\hline$\$ 100.01-\$ 200.00$ & 6 & 2.9 \\
\hline$\$ 200.01-\$ 400.00$ & 4 & 1.9 \\
\hline$>\$ 400.00$ & 7 & 3.3 \\
\hline
\end{tabular}

Table 3

Reasons for Donating Money to a Charitable Organization in the Past Year

\begin{tabular}{|l|l|}
\hline Reason & $n$ \\
\hline The cause the charity represents has personal significance (e.g., family history of cancer, know someone & 33 \\
\hline
\end{tabular}




\begin{tabular}{|l|c|}
\hline who benefited from services provided by the charity) & 31 \\
\hline Trust the charity and believe in organizational views/values (e.g., know the money will be put to good use) & 26 \\
\hline The charity benefits a particular population (e.g., children) & 22 \\
\hline Believe charity represents a good or worthy cause & 16 \\
\hline Believe have an obligation to help others/want to help make a difference & 15 \\
\hline Felt sorry for the person asking for money/couldn't say no & 13 \\
\hline To assist research in finding a cure (e.g., for cancer) & 10 \\
\hline Opportunistic reasons (e.g., door knock appeal) & \\
\hline
\end{tabular}

Note. Participants may have provided multiple reasons for donation.

Table 4

Reasons for Decision Not to Donate Money to a Charitable Organization When Asked

\begin{tabular}{|l|c|}
\hline \multicolumn{1}{|c|}{ Reason } & $n$ \\
\hline Financial difficulties (i.e., no money to spare, can't afford it) & 34 \\
\hline No interest in or not knowing about the cause the charity is collecting money for & 4 \\
\hline Laziness/can't be bothered & 3 \\
\hline Don't trust the money goes to those who need it & 3 \\
\hline Not having spare change when asked & 2 \\
\hline Dislike being hassled & 2 \\
\hline No opportunity to donate & 1 \\
\hline Someone else in family already donates & 1 \\
\hline Feeling that the act of donating would not be reciprocated if the donor needed money & 1 \\
\hline
\end{tabular}

Note. Participants may have provided multiple reasons for not donating.

Table 5 
Means and Bivariate Correlations for Predictor Variables and Intentions to Donate Money in the Future

\begin{tabular}{|c|c|c|c|c|c|c|c|}
\hline Variable & $M$ & $S D$ & 1 & 2 & 3 & 4 & 5 \\
\hline 1. Attitude & 4.76 & 1.06 & - & & & & \\
\hline $\begin{array}{l}\text { 2. Subjective } \\
\text { norm }\end{array}$ & 3.96 & 1.06 & $.48 * * *$ & - & & & \\
\hline 3. $\mathrm{PBC}$ & 4.78 & 0.91 & $.61 * * *$ & $.46 * * *$ & - & & \\
\hline 4. Moral norm & 3.13 & 1.59 & $.38 * * *$ & $.47 * * *$ & $.30 * *$ & - & \\
\hline 5. Past behavior & 4.56 & 1.13 & $.26 * * *$ & $.14 *$ & $.26 * * *$ & $.25 * * *$ & - \\
\hline 6. Intention & 2.66 & 1.13 & $.65 * * *$ & $.45 * * *$ & $.63 * * *$ & $.50 * * *$ & $.42 * * *$ \\
\hline
\end{tabular}

Note. PBC $=$ perceived behavioral control. Mean scores in the current study are rated on 7-point scales ranging from

0 to 6, except for Past behavior, which is rated on a 5-point scale ranging from 1 to 5.

$* p<.05 . * * p<.01 . * * * p<.001$.

Table 6

Hierarchical Regression Analyses Testing the Extended TPB (Including Moral Norm and Past Behavior) in Predicting Intention to Donate Money in the Future

\begin{tabular}{|c|c|c|c|c|c|c|}
\hline Predictor & $R$ & $R^{2}$ & $\Delta R^{2}$ & $F_{\text {change }}$ & $d f \mathrm{~s}$ & $\beta$ \\
\hline Step 1 & & & & & & \\
\hline Attitude & .72 & .52 & .52 & $72.82^{* * *}$ & 3,204 & $.39 * *$ \\
\hline Subjective norm & & & & & & .10 \\
\hline PBC & & & & & & $.35^{* * *}$ \\
\hline Step 2 & & & & & & \\
\hline Attitude & .76 & .57 & .05 & $25.48 * * *$ & 1,203 & $.34 * * *$ \\
\hline Subjective norm & & & & & & \\
\hline PBC & & & & & & .00 \\
\hline Moral norm & & & & & & $.27 * * *$ \\
\hline
\end{tabular}




\begin{tabular}{|l|l|l|l|l|l|c|}
\hline Step 3 & & & & & & \\
\hline Attitude & .78 & .61 & .03 & $17.75^{* * *}$ & 1,202 & $.32^{* * *}$ \\
\hline Subjective norm & & & & & & .01 \\
\hline PBC & & & & & & $.31^{* * *}$ \\
\hline Moral norm & & & & & & $.23^{* * *}$ \\
\hline Past behavior & & & & & & $.19^{* * *}$ \\
\hline
\end{tabular}

Note $. \mathrm{TPB}=$ theory of planned behavior; $\mathrm{PBC}=$ perceived behavioral control.

$* * p<.01 . * * * p<.001$.

${ }^{\mathrm{A}}$ INSERT TABLE 1 ABOUT HERE

${ }^{B}$ INSERT TABLE 2 ABOUT HERE

${ }^{\mathrm{C}}$ INSERT TABLE 3 ABOUT HERE

${ }^{D}$ INSERT TABLE 4 ABOUT HERE

${ }^{\mathrm{E}}$ INSERT TABLE 5 ABOUT HERE

${ }^{\mathrm{F}}$ INSERT TABLE 6 ABOUT HERE 